\title{
INTUSSUSCEPTION, THE FIRST SIGN IN A PATIENT WITH INTESTINAL LYMPHOMA DUE TO AIDS A RARE CASE REPORT
}

\author{
P. Naresh Kumar1, P. Karuppasamy², K. Prasanna Venkatesan³, K. Anitha ${ }^{4}$ \\ ${ }^{1}$ Associate Professor, Department of Surgery, Sri Venkateswaraa Medical College and Research Institute. \\ ${ }^{2}$ Assistant Professor, Department of Surgery, Sri Venkateswaraa Medical College and Research Institute. \\ ${ }^{3}$ Consultant Surgeon, Sri Ezhumalayan Nursing Home, Pattukkottai. \\ ${ }^{4}$ Consultant Gynaecologist, Sri Ezhumalayan Nursing Home, Pattukkottai.
}

\begin{abstract}
Although, intussusception is a common cause of intestinal obstruction in children, it is a rare event in the adult population. It has long been known that various acquired immune deficiency syndrome related conditions of the bowel such as lymphoma, lymphoid hyperplasia, cytomegalovirus colitis and Kaposi's sarcoma can lead to intussusception. The diagnosis is particularly difficult in this population of patients due to the non-specific nature of the symptoms as well as the depressed immune response obscuring inflammation or ischemia. Though the reported acquired immune deficiency syndrome associated cases of intussusception refer to patients with known human immunodeficiency virus infection, in our case we present an intestinal intussusception as the first manifestation of human immunodeficiency virus infection.
\end{abstract}

\section{CASE PRESENTATION}

A 50-year-old heterosexual woman with a clean medical record and no history of abdominal operation presented to our ER with symptoms and signs suggestive of bowel obstruction. Plain abdominal radiographs were highly suspicious for intussusception, which we confirmed on a computed tomography scan. The patient was prepared for surgery and on routine investigations before surgery serology confirmed retroviral disorder, the patient was operated 3 days later and this confirmed the diagnosis of small-bowel invagination due to a $4 \mathrm{~cm}$ polypoid growing intraluminal tumor, the pathologic examination of which revealed a diffuse high-grade B cell lymphoblastic lymphoma.

\section{CONCLUSION}

Human immunodeficiency virus infection may have a silent course and gastrointestinal manifestations of the disease leading to intussusception might be the first clinical sign. Patients with intestinal intussusception and the presence of risk factor s for human immunodeficiency virus infection should be eligible for serologic tests for human immunodeficiency virus infection.

\section{KEYWORDS}

HIV: Human Immunodeficiency Virus; AIDS: Acquired Immune Deficiency Syndrome; CMV: Cytomegalovirus; CD4: Cluster of Differentiation 4; CT: Computed Tomography, Intussusception.

HOW TO CITE THIS ARTICLE: Kumar PN, Karuppasamy P, Venkatesan KP, et al. Intussusception, the first sign in a patient with intestinal lymphoma due to aids a rare case report. J. Evolution Med. Dent. Sci. 2016;5(13):604-606, DOI: 10.14260/jemds/2016/137

\section{INTRODUCTION}

Intussusception comes from the Latin intussuscipere which means to take in and refers to a bowel that invaginates upon itself. Though intussusception is a common cause of intestinal obstruction in the pediatric population, it is quite uncommon in adults living in temperate regions, representing fewer than $10 \%$ of total causes.[1] Unlike childhood intussusception, which is idiopathic in $90 \%$ of cases, adult intussusception has a demonstrable cause in over $90 \%$ of cases.[2]

An intraluminal tumor, submucosal edema or any process that causes dysrhythmic contractions may initiate intussusception.

Financial or Other, Competing Interest: None.

Submission 29-12-2015, Peer Review 25-01-2016,

Acceptance 01-02-2016, Published 15-02-2016.

Corresponding Author:

Dr. P. Naresh Kumar M. S,

Associate Professor, Department of Surgery,

Sri Venkateswaraa Medical College and Research Institute

E-mail: karuppasamy01@yahoo.co.in

DOI: $10.14260 /$ jemds $/ 2016 / 137$
Colonic intussusception is most commonly caused by a primary carcinoma and benign tumors including submucosal masses and accounts for the majority of cases of intestinal intussusception. ${ }^{[3]}$

There is growing evidence from the literature associating intussusception with Human Immunodeficiency Virus (HIV) infection. ${ }^{[1,3-8]}$ Gastrointestinal manifestations of Acquired Immune Deficiency Syndrome (AIDS) that may potentially initiate an intussusception include lymphoma, lymphoid hyperplasia, Cytomegalovirus (CMV) colitis and Kaposi's sarcoma.[9]

We present a case of intestinal intussusception as the first manifestation of HIV infection in a middle-aged woman.

\section{CASE PRESENTATION}

A 50-year-old, heterosexual woman with a clean medical record and no history of abdominal operation presented to the emergency department with a 2-week history of gradually worsening abdominal pain. Though the patient had been experiencing flatus daily, she reported no bowel movements over the last 5 days. Furthermore, the patient had worsening 
nausea and vomiting as well as abdominal distention leading to inability to tolerate oral intake.

Physical examination revealed a well-nourished, mildly febrile patient $\left(37.5^{\circ} \mathrm{C}\right)$. She was hemodynamically stable and her abdomen though soft was distended and tender in the hypogastrium and right lower quadrant. No hernia was apparent. Bowel sounds were sluggish and rectal examination showed heme-positive stools. Laboratory tests revealed a peripheral leukocyte count of $5080 / \mu \mathrm{l}$ with a normal differential count and a hematocrit of $30 \%$. Electrolytes, liver biochemistry and amylase levels were normal.

Plain abdominal radiographs showed multiple air-fluid levels in distended small-bowel loops and air in the colon indicating partial small bowel obstruction (Figure 1). A Computed Tomography (CT) scan of the abdomen revealed dilated loops of the small intestine and a transition point to decompressed loops at the level of the mid-ileum as well as a typical 'Target sign' or 'Doughnut sign' of intussusception (Figure 2).

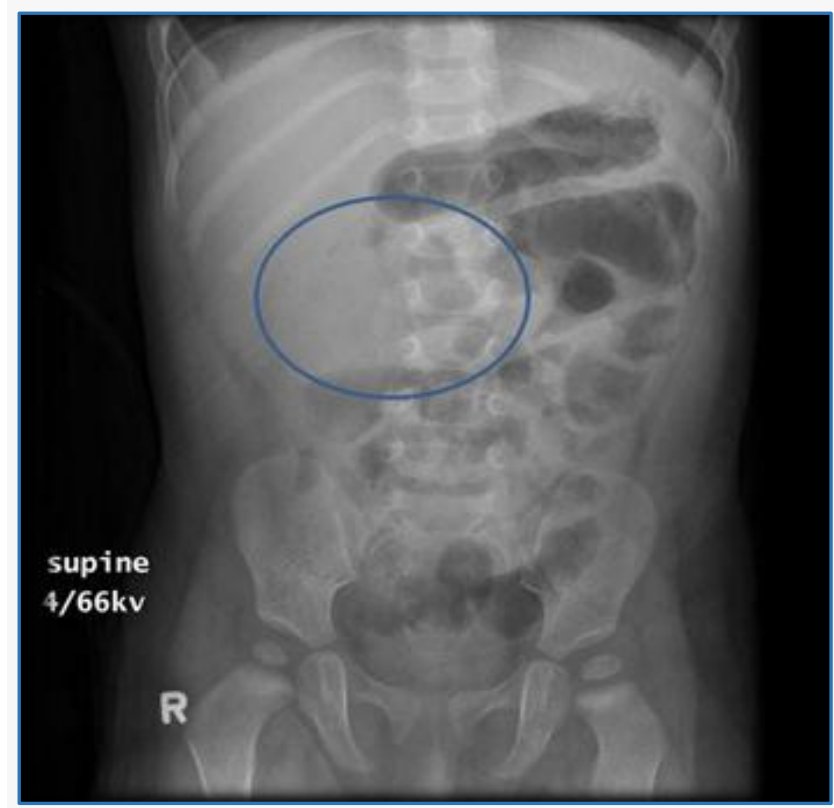

Fig. 1: Plain abdominal radiograph showing dilated loops of small bowel in the right hemiabdomen and a soft tissue mass

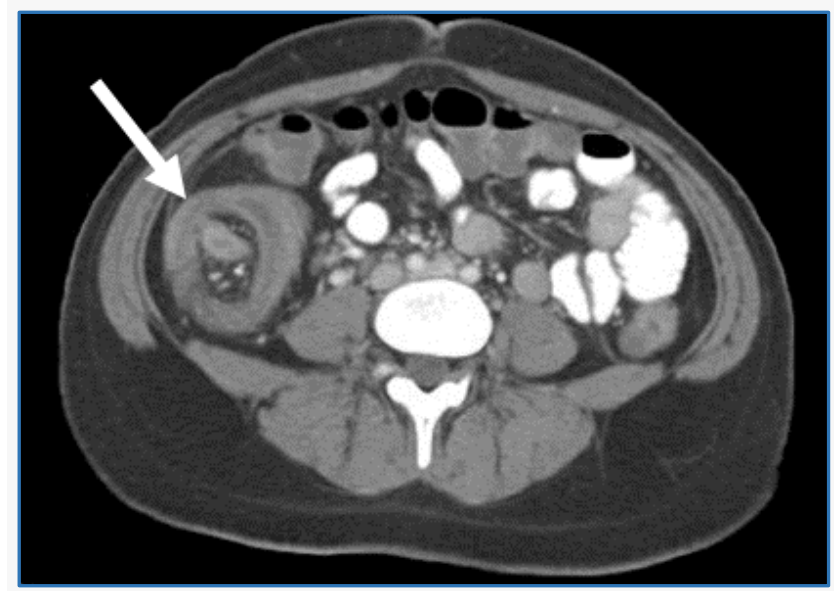

Fig. 2: Contrast enhanced abdominal tomography at the level of the umbilicus showing a characteristic 'target mass' (Arrows) in the right abdomen
The patient was investigated further for surgery. Surprisingly, the patient was seropositive for HIV infection and had a cluster of differentiation 4 (CD4) cell count of $274 / \mu \mathrm{l}$ and viral load of 129,000 copies/ml.

Laparotomy was performed 3 days later, the diagnosis of small-bowel invagination due to a $4 \mathrm{~cm}$ polypoid growing intraluminal tumor (Figure 3). Pathologic examination of the specimen revealed a diffuse high-grade B cell lymphoblastic lymphoma. The patient had an uneventful recovery and was discharged from hospital on the $6^{\text {th }}$ postoperative day.

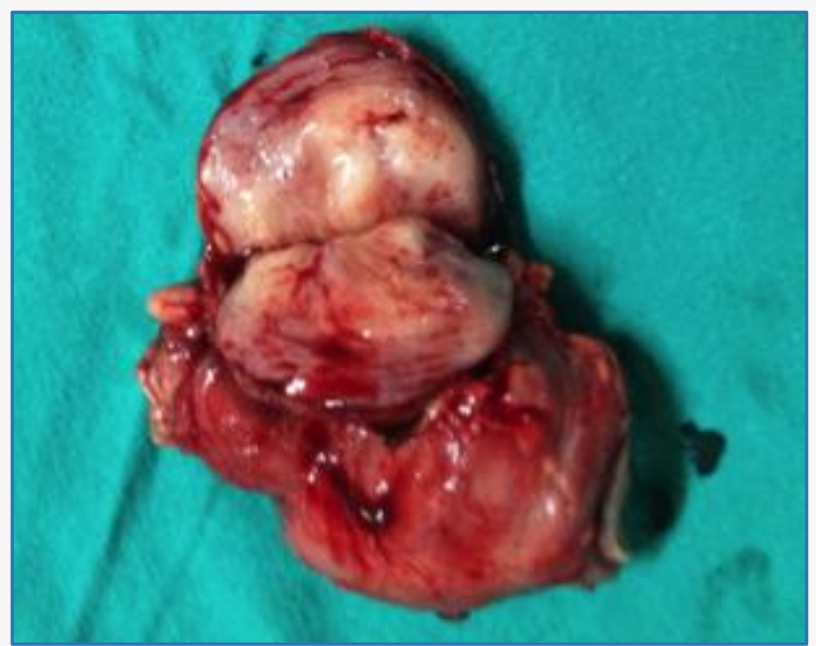

Fig. 3: Resected small bowel segment showing an intraluminal growing mass (Arrows) as the underlying reason for the intussusception

Pathologic examination of the specimen revealed a diffuse high-grade B cell lymphoblastic lymphoma.

\section{DISCUSSION}

Bowel obstruction is one of the most common complaints driving patients to our emergency department. In the vast majority of cases, a history of previous abdominal operation is revealed making adhesions the leading cause of intestinal obstruction. Other less common causes of intestinal obstruction include incarcerated hernias, malignant disease and inflammatory bowel disease. In cases of intestinal obstruction where the above pathologic conditions are not revealed, it is a real challenge for the surgeon to undertake the diagnosis.

Though a common cause of intestinal obstruction in children, intussusception is a rare event in the adult population living in temperate regions, accounting for only 2 to 3 cases per 1 million population reported annually.[1]

It has long been known that various AIDS-related conditions of the bowel can lead to intussusception.[10,11] Nonetheless, the diagnosis is particularly difficult in this population of patients due to the non-specific nature of the symptoms as well as the depressed immune response leading to low leukocyte count and thus obscuring any inflammation or ischemia.[6]

Contrast-enhanced CT of the abdomen is the diagnostic tool of choice. Intussusception has a pathognomonic appearance on CT scan, the 'Target sign,' with a visible appearance of an outer bowel wall circumscribing the inner wall. Additionally, a hypodense area which represents 
invaginated mesenteric fat is often apparent within the intussusceptum.

Intussusception appears to be more common in HIV infected patients due to the increased incidence of pathologic small bowel processes. ${ }^{[12,13]}$ The interesting feature of our case is that our patient did not have a documented HIV infection. Instead, it was his clean medical record as well as the radiologic diagnosis of intussusception that prompted us to undertake further serologic tests and eventually to establish the diagnosis.

We are aware of cases of intussusception in HIV patients reported elsewhere in the literature.[1,4-6,8,9] However, we believe that this is a rare case of silent HIV infection diagnosed via a gastrointestinal manifestation of the disease.

\section{CONCLUSION}

Though a rare cause of intestinal obstruction in adults, intussusception has been shown to have a significant correlation with HIV infection because of its association with a variety of infective and neoplastic conditions of the bowel. Apparently, HIV infection may have a silent course and gastrointestinal manifestations of the disease leading to intussusception might be the first clinical sign. Therefore, patients with intestinal intussusception and the presence of risk factors for HIV infection should be eligible for serologic tests for HIV infection. In these patients, surgical reduction in the intussusception is well tolerated and is of clear benefit.

\section{ABBREVIATIONS}

HIV: Human Immunodeficiency Virus; AIDS: Acquired Immune Deficiency Syndrome; CMV: Cytomegalovirus; CD4: Cluster of Differentiation 4; CT: Computed Tomography

Competing Interests

\section{REFERENCES}

1. Blazes DL, Lipscomb SJ, Schoenfeld PS, et al. Intussusception in an HIV infected patient: a case report and review of the literature.

AIDS Read 2001;11:525-528. PubMed Abstract.

2. Agha FP. Intussusception in adults.

AJR 1986;146:527-531. PubMed Abstract | Publisher Full Text.
3. Silverman PM, Hayes WS, Cooper CJ, et al. Abdominal case of the day. AJR 1990;154:1325-1330. PubMed Abstract | Publisher Full Text.

4. Balthazar EJ, Reich CB, Pachter HL. The significance of small bowel intussusception in Acquired Immune Deficiency Syndrome. Am J Gastroenterol 1986;81:10731075. PubMed Abstract.

5. Meyerson S, Desai TK, Polidori G, et al. A case of intussusception and lymphoid hyperplasia in a patient with AIDS. Am J Gastroenterol 1993;88:303-306. PubMed Abstract.

6. Visvanathan R, Nichols TT, Reznek RH. Acquired immune deficiency syndrome-related intussusception in adults. Br J Surg 1997;84:1539-1540. PubMed Abstract । Publisher Full Text.

7. Wetter A, Schaudt A, Lehnert T, et al. Small-bowel intussusception as a rare differential diagnosis in HIVpositive patients with acute abdomen.

Eur Radiol 2006;16:952-953. PubMed Abstract | Publisher Full Text.

8. Farrier J, Dinerman C, Hoyt DB, et al. Intestinal lymphoma causing intussusception in HIV+ patient: a rare presentation. Curr Surg 2004;61:386-389. PubMed Abstract | Publisher Full Text.

9. Hofstetter SR, Stollman N. Adult intussusception in association with acquired immune deficiency syndrome and intestinal Kaposi's sarcoma. Am J Gastroenterol 1986;83:1304-1305. PubMed Abstract.

10. Wood BJ, Kumar PN, Cooper C, et al. AIDS-associated intussusception in young adults. J Clin Gastroenterol 1995;21:158-162. PubMed Abstract | Publisher Full Text.

11. Wilson SE, Robinson G, Williams RA, et al. Acquired immune deficiency syndrome (AIDS). Indications for abdominal surgery, pathology and outcome. Ann Surg 1989;210:428-434. PubMed Abstract | Publisher Full Text |PubMed Central Full Text.

12. Chambers AJ, Lord RSA. Incidence of acquired immune deficiency syndrome (AIDS)- related disorders at laparotomy. Br J Surg 2001;88:294-297. PubMed Abstract | Publisher Full Text.

13. Clayton F, Clayton C. Gastrointestinal pathology in HIVinfected patients.

Gastroenterol Clin 1997;26:191-240. Publisher Full Text. 